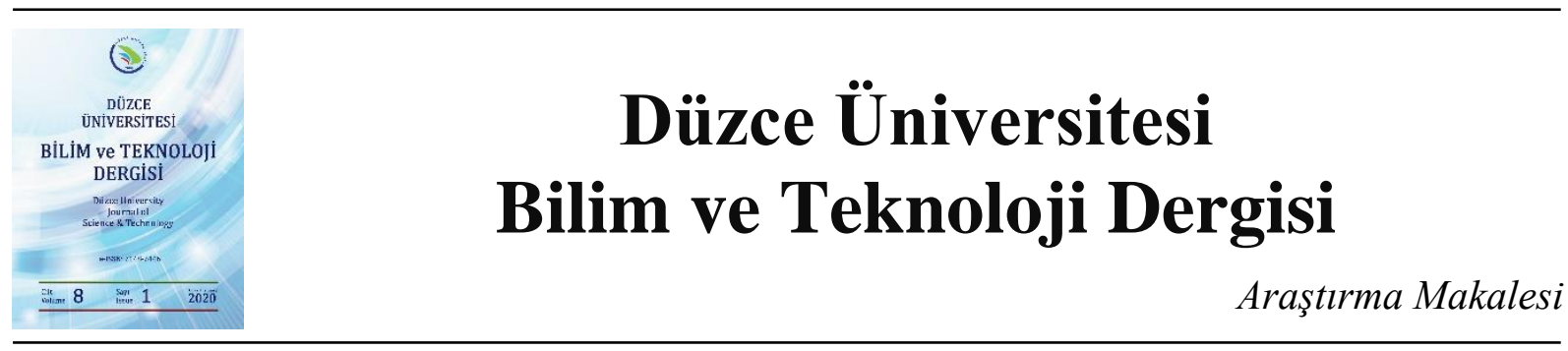

\section{Mükemmel İletken Silindir Modeli ile 28 GHz'de İç Mekân Linklerini Bloke Eden İnsanların Etkilerinin İrdelenmesi}

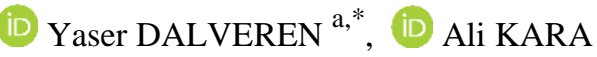 \\ ${ }^{a}$ Uçak Elektrik-Elektronik Bölümü, Sivil Havacılık Yüksekokulu, Atıllm Üniversitesi, Ankara, TÜRKIYE \\ ${ }^{b}$ Elektrik ve Elektronik Mühendisliği Bölümü, Atılım Üniversitesi, Atılım Üniversitesi, Ankara, TÜRKIYE \\ * Sorumlu yazarin e-posta adresi: yaser.dalveren@atilim.edu.tr
}

DOI: 10.29130/dubited.605614

\begin{abstract}
ÖZET
Literatürde, kısa mesafe iç mekân haberleşme linklerinde insan vücudu blokajının sebep olduğu kaybın tahmininde matematiksel olarak sade bir yapıya sahip olması sebebiyle Çift Bıçak Kenarlı Kırınım (ÇBKK) modeli sıklıkla kullanılmaktadır. Fakat modelde insan vücudu benzetimi için kullanılan dikdörtgensel ekran, insan vücudu fiziğini temsil etmek için yeterli olmayabilir. Bu durum, özellikle çoklu insan vücudu blokaj1 olması durumunda, modelin tahmin doğruluğunu olumsuz etkileyebilir. Öte yandan, insan vücudu benzetiminde Geometrik Kırınım Teorisi (GKT) temelli mükemmel iletken silindir modeli, literatürde sıklıkla kullan bir diğer modeldir. Ancak bu modelin, çoklu insan vücudu blokajı durumunda, yayılım kaybını tahmin etmedeki etkisi henüz çalışılmamıştır. Bu nedenle, sunulan bu kısa çalışmadaki amaç, iletken silindir modelinin, $5 \mathrm{G}$ için tahsis edilmesi en muhtemel frekans bantlarından biri olan $28 \mathrm{GHz}$ 'de, çoklu insan vücudu blokajının neden olduğu kısa mesafe iç mekân linklerindeki yayılım kaybını tahmin etmedeki doğruluğunu irdelemektir. Bu amaçla, öncelikle, kısa mesafe iç mekân linki bir insan vücudu ile tamamen bloklanmış; aynı anda, link yakınındaki başka bir insan vücudu linke yaklaştırılarak ölçümler yapılmıştır. Sonrasında, yayılım kaybını tahmin etmek için GKT ve ÇBKK modelinden faydalanılmıştır. Tahmin doğruluğu analizi için simülasyon ve ölçüm sonuçları karşılaştırılmıştır. Sonuç olarak deneysel çalışmalar ile literatürde ilk defa, çoklu insan vücudu blokajının GKT modeli ile tahmin doğruluğunun arttığı gözlemlenmiştir.
\end{abstract}

Anahtar Kelimeler: 5G, Mükemmel iletken silindir, Geometrik kırınım teorisi, Çift bıçak kenarlı kırınım, Yayılım kaybl

\section{Examining the Effects of Human Bodies Blocking Indoor Links at 28 GHz with a Perfectly Conducting Cylinder Model}

\begin{abstract}
In the literature, due to its mathematically tractable nature, Double Knife-Edge Diffraction (DKED) model is often used to predict the loss caused by human body blockage in short-range indoor links. However, the rectangular screen used to simulate the human body in the model may insufficient to represent the physics of human body. This adversely affects the prediction accuracy of the model especially in the presence of multiple human blockage events. On the other hand, perfectly conducting cylinder model based on Geometrical Theory of
\end{abstract}


Diffraction (GTD) is another well-known model used in the literature. Yet, the prediction accuracy of this model has not been studied in the case of multiple human blockage. Therefore, the purpose of this letter is to examine the accuracy of conducting cylinder model in predicting propagation loss due to multiple human blockage in short-range indoor links at $28 \mathrm{GHz}$, one of the most probable frequency bands allocated for 5G. To this end, firstly, a short-range indoor link was fully blocked by a human body, meanwhile, another human body around the link was approached to the link, and measurements were conducted. Then, GTD and DKED model were utilized to predict the propagation loss. In order to analyze the prediction accuracy of the models, measurement and simulation results were compared. As a result, for the first time in the literature, it has been observed that the prediction accuracy of multiple human body blockage is increased by using GTD-based model with experimental studies.

Keywords: 5G, Perfectly conducting cylinder, Geometrical theory of diffraction, Double knife-edge diffraction, Propagation loss

\section{GIiRIS}

Son yıllarda, gelişen teknoloji ile birlikte akıllı telefon ve tablet bilgisayar kullanımı insanlar arasında oldukça yaygınlaşmıştır. Özellikle nihai kullanıcıların sosyal medyayı aktif olarak kullanması, yüksek veri hızına olan talebi ciddi oranda artırmaktadır. Bu bağlamda, yeni bir iletişim nesli olarak, beşinci nesil (5G) kablosuz bağlantı teknolojisinin bu talebi karşılayacağı beklenmektedir [1,2]. 5G teknolojisinde, milimetre dalga (mmWave) bandi civarında $(28-33 \mathrm{GHz})$ band tahsisi kullanılması üzerinde çalışmalar devam etmektedir. Böylelikle, yüksek hızlarda veri erişiminin sağlanması mümkün olacaktır. Fakat dalga boyunun kısa olması sebebiyle, yüksek frekanslı radyo dalgalarının çevresel faktörler (yeryüzü şekilleri, yapılar vb.) tarafından kolaylıkla bloke edilmesi kaçınılmazdır. Bu durumda, özellikle iç mekân çevresel faktörlerinin 5G haberleşme sistemleri üzerindeki etkisinin değerlendirilmesi önem arz etmektedir.

Ev ve ofis gibi iç mekânlar göz önünde bulundurulduğunda, insan vücudunun kablosuz haberleşme linkleri için blokaj problemi oluşturarak yayılım kaybına sebep olan en önemli etmenlerden biri olduğu bilinmektedir. $\mathrm{Bu}$ nedenle, farklı milimetre dalga bantlarında insan vücudu blokajının link üzerindeki etkileri literatürde birçok çalışma tarafından incelenmiştir [3-9]. Bu çalışmalarda, insan vücudu blokajının sebep olduğu yayılım kaybının kestirimi için çeşitli modeller kullanılmıştır. Bunlardan en yaygın olarak kullanılanları Geometrik Kırınım Teorisi (GKT) temelli mükemmel iletken silindir modeli [4,5] ve Çift Bıçak Kenarlı Kırınım (ÇBKK) temelli dikdörtgensel soğurucu ekran modelidir [6].

Öte yandan, 5G için tahsis edilmesi muhtemel frekans bantlarında (28-33 GHz), insan vücudu blokajının iç mekân linkleri üzerindeki etkisini inceleyen çalışma sayısı literatürde oldukça kısıtlıdır [6-10]. Ayrıca, çeşitli yüksek frekans bantlarında iç mekân linklerinin çevresinde bulunan insan ve eşya gibi yansıtıcıların link üzerindeki etkisi literatürde birçok çalışmada irdelenmiş olsa da [11,12], bu frekans bandında yansıtıcı objelerin etkisi sadece [10]'da incelenmiştir. Bahsi geçen çalışmada, yakın gelecekteki 5G kablosuz sistemlerindeki linkleri bloklarken aynı zamanda yakınlarında hareket eden insanların modellenmesi ile ilgili deneysel çalışma destekli model önerisi amaçlanmıştır. $\mathrm{Bu}$ kapsamda, yeni ve basit bir modelin çalışabildiği gösterilmiştir. Buna göre, kısa mesafe iç mekân linki bir insan vücudu ile tamamen bloklanarak çevresinde bulunan yansıtıcıların (metal yansıtıcı ve insan vücudu) etkisi karakterize edilmiştir. Bunu yaparken, yansıma ve kırınım gibi dalga yayılımının temel 
mekanizmaları dikkate alınmıştır. Metalik yansıtıcının sebep olduğu yayılım kaybını tahmin edebilmek için düzgün yansıma modeli kullanılırken; insan vücudunun sebep olduğu yayılım kaybını tahmin edebilmek için basit bir kırınım modeli kullanılmıştır. Kırınım modelinde insan vücudunun neden olduğu yayılım kaybını tahmin etmede, matematiksel olarak basit ve kolay uygulanabilir olması sebebiyle, ÇBKK modelinden faydalanılmıştır. Benzetim ve ölçüm sonuçları karşılaştırılmış ve her iki yayılım modeli için de belirli bir hata marjı içerisinde tutarlı sonuçlar elde edilmiştir. Özellikle kırınım modeli için elde edilen sonuçların ölçüm sonuçlarıyla daha çok örtüştügü gözlemlenmiştir. Böylelikle, gelecekteki 5G kablosuz sistemlerinde haberleşme linklerini engelleyen ve link civarında hareket eden insanların en basit şekilde modellenebileceği hususunda ümit verici sonuçlar elde edilmiştir.

ÇBKK modeli, insan blokajından kaynaklı yayılım kaybını tahmin etme doğruluğu bakımından bir noktaya kadar yeterli bir model olmasına rağmen, insan vücudu benzetiminde kullanılan dikdörtgensel ekranın, insan vücudu fiziğini temsil ettiği söylenemez. Bunun bir sonucu olarak, ÇBKK modelinin tahmin doğruluğu blokajın link üzerindeki pozisyonuna bağlı olarak bazı durumlarda düşmektedir [6]. Modelin uygulanabilirlik sınırları [13]'te detaylıca tartışılmıştır. Bu durum ayrıca, çoklu insan blokaj1 durumunda tahmin doğruluğunu da olumsuz etkileyebilir. Fakat insan vücudunun sebep olduğu yayılım kaybını tahmin etmede sıklıkla kullanılan bir diğer model olan GKT temelli mükemmel iletken silindir modeli, her ne kadar ÇBKK modeline göre matematiksel olarak daha karmaşık bir yapıya sahip olsa da, elektromanyetik dalga etkileşimini daha doğru ifade ettiği düşünülmektedir. Bu bağlamda, bu kısa makalede sunulan çalışmanın amacı, 28 GHz'deki kısa mesafe iç mekân linklerinde çoklu insan blokajı olması durumunda, insan vücudunun GKT temelli mükemmel iletken silindir modeli ile benzetiminin yayılım kaybı tahmin doğruluğu üzerindeki etkisini araştırmaktır. Bu amaç doğrultusunda, öncelikle, çoklu insan blokajı modellemesi için [10]'da kullanılan yaklaşımdan ve deneysel ölçümlerden faydalanılarak insan vücutlarının neden olduğu kayıp GKT ve ÇBKK kullanılarak hesaplanmış ve yapılan çalışmada benzetim sonuçları, ölçüm sonuçları ile karşılaştırılmıştır. Sonuç olarak, GKT temelli mükemmel iletken silindir modeli kullanılarak elde edilen benzetim sonuçlarının ÇBKK modeline kıyasla deneysel ölçüm değerleri ile daha iyi örtüştüğü gözlemlenmiştir. Dolayısıyla, insan vücudu benzetiminde mükemmel iletken silindir modelinin kullanımı ile gelecekteki 5G kablosuz haberleşme sistemlerinde kısa mesafe iç mekân linklerini bloklayan ve link civarında hareket eden insanların sebep olacağı yayılım kaybının daha doğru şekilde tahmin edilebileceği sonucuna varılmıştır.

Çalışmanın devam eden bölümünde kullanılan ölçüm sistemi ve ölçüm senaryoları anlatılmıştır. Sonrasında, çoklu insan blokajı modellemesi için çalışmada kullanılan yaklaşımın detayları açıklanmıştır. Dördüncü bölümde, model sonuçları sunularak deneysel ölçüm sonuçları ile karşılaştırılmıştır. Son bölümde ise sonuçlar ve gelecekte yapılması planlanan çalışmalar açıklanmıştır.

\section{II. ÖLCÜM SISTEMI}

Çalışmada kullanılan ölçüm sisteminin detayları [10]'da açıklanmıştır. Genel olarak sistem; alıcı anten, verici anten, spektrum analizörü ve sinyal üreticisinden oluşmaktadır. Sistemde $20 \mathrm{dBi}$ kazançlı iki özdeş huni anteni (PE9850/2F-20), alıcı ve verici anten olarak kullanılmıştır. Her iki anten de $1 \mathrm{~m}$ uzunluğundaki ayaklıkların üzerine yerleştirilmiştir. $\mathrm{Bu}$ antenler arası uzaklık $2 \mathrm{~m}$ olarak belirlenmiştir. Verici anten, Agilent E8244A sinyal üreticisine bağlanmışken; alıcı anten, Agilent E4448A izge çözümleyicisine bağlanmıştır. Bu bağlantılar için düşük kayıplı kablolar kullanılmıştır. 
Çalışmadaki tüm ölçümler, Atılım Üniversitesi RF ve anten laboratuvarında gerçekleştirilmiştir. Ölçümlerin gerçekleştirildiği laboratuvar ortamı ve ölçüm sistemi Şekil 1'de gösterilmiştir.

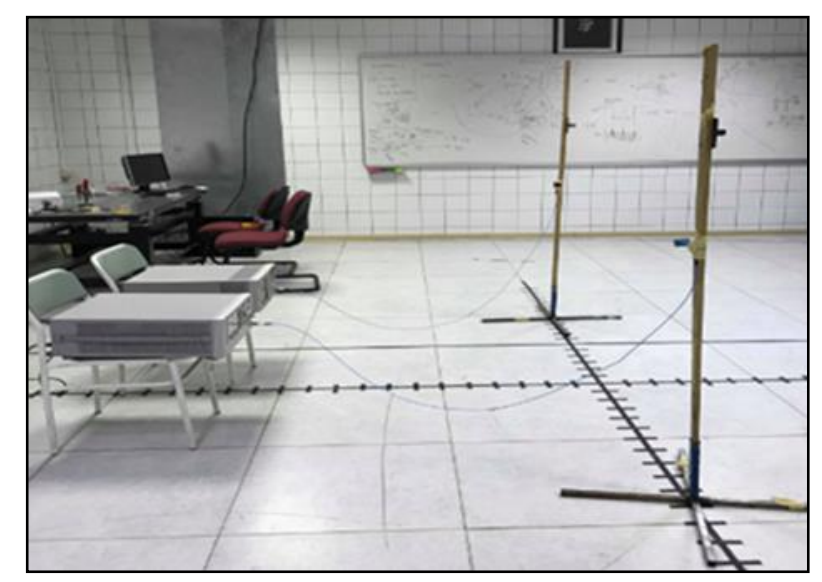

Şekil 1. Ölçüm sistemi

İdeal ölçüm koşullarını sağlamak için ölçümlerin öncesinde bazı ön çalışmalar yapılmıştır. Bu çalışmalar kapsamında ilk olarak sistem kalibrasyonu yapılmıştır. Ardından, ortamdaki sabit yansitıcılardan kaynaklanan çok yollu sinyallerin etkileri incelenmiştir. Buna göre, ortamdaki muhtemel yansıtıcı nesnelerin konumları dikkate alındığında, çok yollu yansımaların ihmal edilebileceği sonucuna varılmıştır.

Ölçümler sırasında alınan güç, insan blokajının adım adım hareket ettirilmesiyle ile ölçülmüştür. Ölçümler, ölçüm sisteminin kararlılığından emin olabilmek için, insan blokajının her pozisyonunda üçer kez tekrarlanmıştır. Sonrasında, bu değerlerin ortalaması alınarak her bir pozisyondaki ölçüm değerleri kaydedilmiştir. Çalışmada gerçekleştirilen ölçüm senaryolarından aşağıda kısaca bahsedilmiştir.

\section{A. SENARYO I - LINK ÜZERINDEN GEÇEN İNSAN VÜCUDU}

Bu senaryoda, Şekil 2'de gösterildiği gibi, 0,5 m omuz genişliğindeki bir birey, link üzerinden yanlamasına geçerken alınan güç ölçülmüştür. Ölçüm boyunca birey, -1 m'den 1 m'ye kadar 10 cm'lik adımlarla hareket ettirilmiştir. Böylece toplamda 21 noktadan ölçüm alınmıştır.

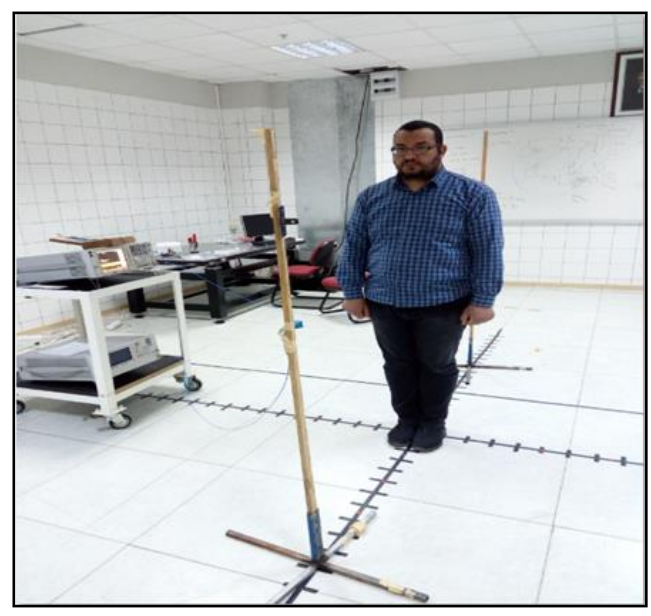

Şekil 2. Ölçüm senaryosu I 


\section{B. SENARYO II - BİR İNSAN VÜCUDU İLE BLOKLANAN LİNKE BAŞKA BİR INSAN VÜCUDUNUN YAKLAŞMASI}

$\mathrm{Bu}$ senaryoda, çoklu insan blokajının modellenmesi için [10]'da kullanılan ölçüm senaryosundan yararlanılmıştır. Buna göre, 0,5 m omuz genişliğine sahip bir birey linki bloklarken, linke doğru 0,47 m omuz genişliğine sahip başka bir birey yaklaştırılmıştır. Ölçümler sırasında, bireylerin çarpışmasını engellemek için linke doğru yaklaşan birey -1 m'den sadece $-0,6$ m'ye kadar hareket ettirilmiştir. Bu durumda alınan güç, her $10 \mathrm{~cm}$ 'de bir olmak üzere toplamda 5 noktadan ölçülmüsstür..

\section{GKT TEMELLI MÜKEMMEL İLETKEN SILINDIIR MODELİ KULLANARAK COKLU INSSAN BLOKAJININ MODELLENMESI}

Çoklu insan blokajının modellenmesi için yazarlar tarafından yapılan bir önceki çalışmada [10], ikinci senaryodaki yayılım modeli kurgulanarak basit bir öneri sunulmuştur. Senaryodaki insan vücudu blokajını modelleyebilmek için basitlik adına ÇBKK modeli kullanmıştır. ÇBKK modelinde, insan vücudu benzetimi için kullanılan ince dikdörtgensel ekran sonsuz yükseklikte kabul edilmektedir. $\mathrm{Bu}$ sebeple, kırınım kaybının ekranın sadece iki yan kenarında oluştuğu farz edilir. ÇBKK modeli, matematiksel olarak sade bir yapıya sahiptir. Bu sayede, insan vücudu blokajından kaynaklı yayılım kaybı, basit ve hızlı şekilde tahmin edilebilmektedir. Bu nedenle, çoklu insan blokajı modellenmesinde tercih edilebilecek oldukça etkili bir model olduğu söylenebilinmektedir. Ancak modelde kullanılan ince dikdörtgensel ekran, insan vücudu fiziğini yansıtmada yetersiz olabilmektedir. Dolayısıyla, modelin yayılım kaybını tahmin etmedeki doğruluğu, blokajın link üzerindeki pozisyonuna bağlı olarak bazı durumlarda azaltılabilmektedir. Ayrıca, yönlü antenler dikkate alındığında, anten kazançları da modelin tahmin doğruluğunu önemli derecede etkileyebilmektedir. Bu bağlamda, ÇBKK modeline alternatif olarak, insan vücudu blokajının sebep olduğu yayılım kaybının kestirimi için literatürde yaygın olarak kullanılan modellerden biri olan GKT temelli mükemmel iletken silindir modeli alternatif olarak tercih edilebilinmektedir.

Bir mükemmel iletken silindirin çevresindeki kırınım, Şekil 3 yardımıyla daha iyi anlaşılabileceği gibi, analitik olarak hesaplanabilmektedir [5, 14].

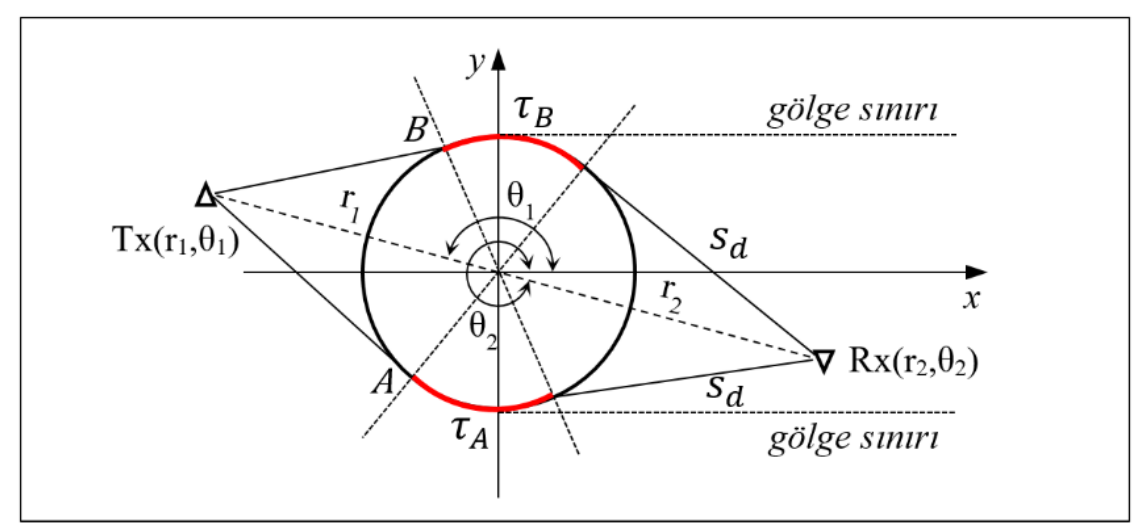

Şekil 3. Mükemmel iletken silindirde kırınım 
Böylelikle, Rx noktasında ölçülen kırınıma uğramış elektrik alan $\left(E_{z}\right)$ aşağıdaki gibi ifade edilebilir

$E_{z}=\sum_{n=1}^{N} D_{n}^{e} E_{i} \frac{\exp \left(-j k s_{d}\right)}{\sqrt{8 j k s_{d}}}\left[\exp \left\{-\left(j k+\Omega_{n}^{e}\right) \tau_{B}\right\}+\exp \left\{-\left(j k+\Omega_{n}^{e}\right) \tau_{A}\right\}\right]$

Eşt. 1'de $D_{n}$ ve $M$ aşağıdaki gibi verilebilir

$D_{n}=2 M\left\{\operatorname{Ai}^{\prime}\left(-\alpha_{n}\right)\right\}^{-2} \mathrm{e}^{j \pi / 6}, M=(k a / 2)^{1 / 3}$.

Burada, $-\alpha_{n}$ Airy fonksiyon türevini $\left(\operatorname{Ai}^{\prime}(\cdot)\right)$ sifirlayan değeri, $k$ dalga sayısını, ve $a$ silindirin yarıçapını temsil etmektedir.

Ek olarak, $E_{i}, A$ ve $B$ sıyırma noktalarındaki elektrik alanı; $\tau_{A, B}$ gelen 1şılların silindir boyunca yol aldığı mesafeyi; $\Omega_{n}^{e}$ ise gelen ışınları zayıflatmaya sebep olan zayıflatma sabitini ifade etmektedir. Elektrik alan için bu sabit aşağıdaki eşitlik kullanılarak hesaplanmaktadır

$\Omega_{n}^{e}=\frac{\alpha_{n}}{a} M \mathrm{e}^{j \pi / 6}$

Dolayısıyla, mükemmel iletken silindirde kırınım kaybı dB cinsinden aşağıdaki gibi ifade edilmektedir

$S L_{G K T}=-20 \log _{10}\left|E_{z}\right|$

$\mathrm{Bu}$ çalışmada öncelikle modelin uygulanabilirliğinden emin olabilmek için önceki bölümde sunulan Senaryo I oluşturulmuştur. Böylece, senaryodaki insan vücudunun neden olduğu kayıp Eşt. 4 kullanılarak hesaplanmıştır. Öte yandan, Senaryo II'de, linki bloke eden insan vücudu ve linke doğru yaklaşarak yansımaya sebep olan diğer bir insan vücudu bulunmaktadır. Burada, her iki insan vücudunun benzetimi için de mükemmel iletken silindir modeli kullanıldığında, alınan güç $\left(P_{r}\right)$ basitçe

$P_{r}=P_{t}+G_{T x}+G_{R x}-P L$

olarak hesaplanabilir [15]. Eşt. 5'te, $P_{t}$ iletilen gücü; $G_{T x}$ normalize edilmiş verici anten kazancını; $G_{R x}$ normalize edilmiş alıcı anten kazancını; $P L$ ise toplam kaybı ifade etmektedir. Toplam kaybın karakteristiğini inceleyebilmek için kırınım prensibi dikkate alınması gerekmektedir. Açıkçası, Tx'den Rx'e olan yayılım, linki bloklayan silindirde meydana gelen kırınımla beraber, linke doğru hareket eden silindirde meydana gelen kırınım olarak gözlemlenebilmektedir. Bu durumu dikkate alan yayılım modeli Şekil 4'te verilmiştir.

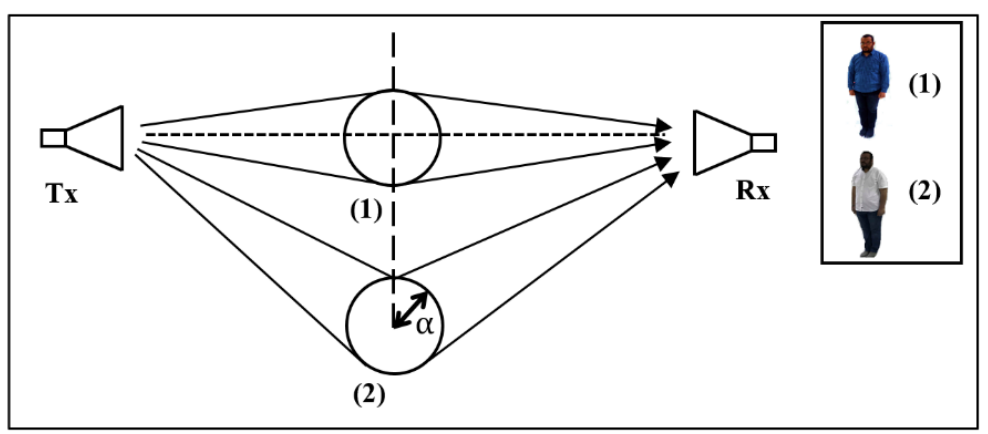

Şekil 4. Senaryo II için yayılım modelinin tepe görünümü 
Böylelikle, $P L$ iki temel bileşenden oluşmaktadır: Bunlardan birincisi; linki bloklayan insan vücudu sebebiyle elektrik alandaki azalma $\left(P L_{1}\right)$, ve ikincisi ise linke yaklaşan insan vücudu sebebiyle elektrik alandaki azalmadır $\left(P L_{2}\right)$. Bu kapsamda, $P L$ basitçe aşağıdaki gibi ifade edilebilmektedir [16]

$P L=P L_{1}+P L_{2}$

Eşt. 6'da, $P L_{1}$ iki bileşenin toplamından oluşmaktadır: Bunlardan birincisi; boş alan yol kaybı $P L_{0}=20 \log _{10}[(4 \pi r / \lambda)]$ (burada, $\lambda$ taşıyıcı dalga boyunu; $r$ ise Tx'den silindire ve silindirden Rx'e olan toplam uzaklığı ifade etmektedir), ve ikincisi ise link merkezindeki insan vücudu için Eşt. 4 kullanılarak hesaplanan $S L_{G K T}$ değeridir. Benzer şeklide, $P L_{2}$ de iki bileşenin toplamından oluşmaktadır: Bunlardan birincisi; $P L_{0}$ değeri, ve ikincisi ise linke yaklaşan insan vücudu için Eşt. 4 kullanılarak hesaplanan $S L_{G K T}$ değeridir. Burada not etmek gerekir ki, $28 \mathrm{GHz}$ 'de dalga boyunun çok kısa olmasından dolayı sinyaller arasındaki faz kaymasının da az olacağı beklenmektedir. Bu nedenle, frekansın çok hızlı değişiminden dolayı, çalışmada faz değişimi ihmal edilerek alınan gücün yerel ortalaması ile ilgilenilmiştir.

\section{IV. ÖLCÜM SONUCLARI}

Bu bölümde, GKT temelli iletken silindir modelinin kısa mesafe iç mekân linklerinde çoklu insan blokajının neden olduğu yayılım kaybını tahmin etmedeki doğruluğunu analiz edebilmek adına ölçüm sonuçları ve benzetim sonuçları karşılaştırılmıştır. Her bir senaryo için elde edilen karşılaştırma sonuçları takip eden alt bölümlerde detaylı bir şekilde incelenmiştir.

\section{A. SENARYO I}

Bir bireyin link üzerinden yanal olarak geçmesiyle ölçülen güç değişimi ile GKT ve ÇBBK kullanılarak elde edilen benzetim sonucu güç değişimi Şekil 5'te gösterilmiştir. Sonuçlardan gözlemlenebileceği gibi, gölgeleme bölgesinde ölçüm sonuçlarının blokaja karşı çok hassas olduğu açıkça görülmektedir. Bu bölgede maksimum kayıp - $25 \mathrm{~dB}$ olarak ölçülmüşken; iletken silindir modeli ile yaklaşık $-27 \mathrm{~dB}$ olarak tahmin edilmiştir. Dolayısıyla öncelikle, silindir modelinin insan vücudu benzetiminde uygulanabilir bir model olduğu deneysel olarak gösterilmiştir. $\mathrm{Bu}$ sonuç, sonraki kısımda önerilen çoklu insan vücudu modelinin geçerliliğine temel teşkil etmektedir.



Şekil 5. Senaryo I için ölçüm sonuçları ile GKT ve ÇBKK kullanılarak elde edilen benzetim sonuçlarının karşılaş̧tırlması 


\section{B. SENARYO II}

Senaryo II'de sunulan yayılım modeli için çoklu insan vücudu blokajlarının benzetiminde GKT ve ÇBKK kullanılarak elde edilen benzetim sonuçları ile ölçüm sonuçlarının karşılaştırılması Şekil 6'da gösterilmiştir. Sonuçlardan gözlemlenebileceği gibi her iki model de yeterli tahmin doğruluğu sağlayabilmektedir. Ancak, ÇBKK modelinin tahmin doğruluğu, link yakınındaki insan vücudunun linkten uzaklaşması durumunda nispeten düşmektedir. Bunun nedeninin anten kazançları ilgili olabileceği [10]'da detaylıca tartışılmıştır. Bu durumda, GKT temelli iletken silindir modelinin tahmin doğruluğunun kısmen de olsa yüksek olduğu söylenebilir.

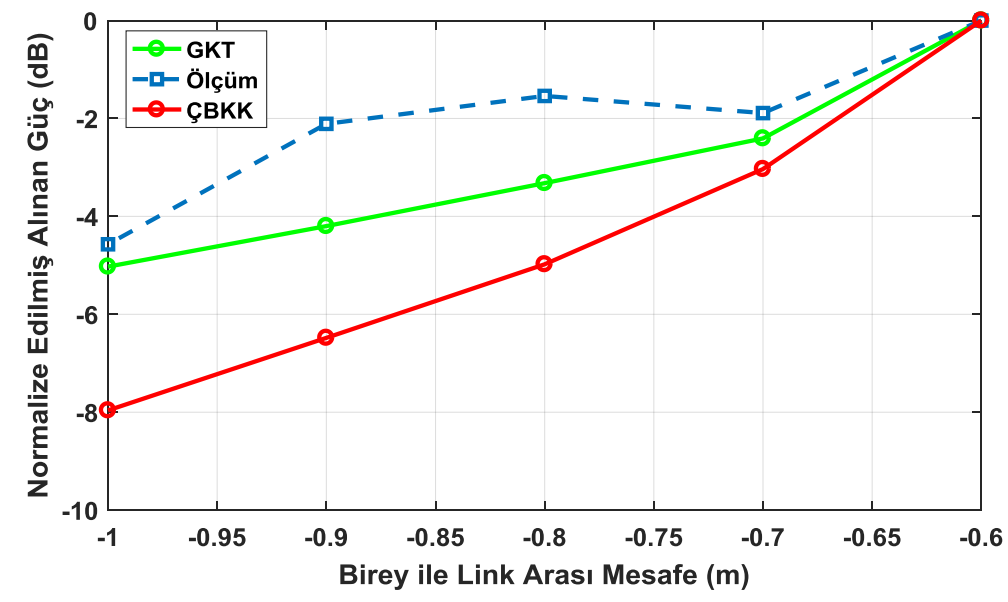

Şekil 6. Senaryo II'deki yayılım modeli için ölçüm sonuçlarının GKT ve ÇBKK modeli kullanarak elde edilen benzetim sonuçları ile karşılaştırılması

\section{V.SONUCLAR}

Literatürde, kısa mesafe haberleşme linkleri üzerinde insan vücudunun neden olduğu kaybın tahmini için matematiksel olarak sade ve kolay uygulanabilir olmasından dolayı ÇBKK modeli tercih edilmektedir. Fakat modelde kullanılan dikdörtgensel ekranın insan vücudunu yansıtmada yeterli olmayabileceği düşünülmektedir. Bu durumda, özellikle çoklu insan blokaj durumunda modelin sağlayacağı tahmin doğruluğunun azalabileceği muhtemeldir. Bu nedenle, bu kısa çalışmada, 5G için tahsis edilen en muhtemel frekans bandında $(28 \mathrm{GHz})$, literatürde yaygın olarak kullanılmakta olan; GKT tekniğiyle insan vücudunun iletken silindir modelinin çoklu insan blokajı modellemesinde kullanılmasının etkisi incelenmiştir. Öncelikle, çoklu insan vücudu blokaj modellemesi laboratuvar ortamında bir insan vücudu tarafından bloklanan kısa mesafe linkine başka bir insan vücudu yaklaştırılarak ölçümler alınmıştır. İnsan vücutlarının neden olduğu kayıp GKT temelli iletken silindir modeli ve ÇBKK modeli kullanılarak hesaplanmış bununla birlikte ölçüm sonuçları ile karşılaştırılmıştır. Sonuç olarak, her iki modelin sağladığı sonuçlar ile ölçüm sonuçları tutarlı olsa da, özellikle link yakınındaki insan vücudunun linkten uzaklaştığı durumlarda, iletken silindir modelin tahmin doğruluğunun nispeten daha yüksek olduğu gözlemlenmiştir. Böylece, çalışmada elde edilen bu sonuçların, iç mekân $5 \mathrm{G}$ kablosuz sistemlerinde haberleşme linkleri üzerinde ve civarında hareket eden insanların modellenebilmesi için yararlı olacağı düşünülmektedir. Bu bağlamda, yazarlar tarafından yakın gelecekte insan blokajı sayısı arttırılarak yeni ölçümlerin ve tahmin doğruluğu analizi için istatistiksel çalışmaların yapılması planlanmaktadır. 


\section{KAYNAKLAR}

[1] T.S. Rappaport, S. Sun, R. Mayzus, H. Zhao, Y. Azar, K. Wang, G.N. Wong, J.K. Schulz, M. Samimi, F. Gutierrez, "Millimeter Wave Mobile Communications for 5G Cellular: It Will Work!", IEEE Access, vol. 1, pp. 335-349, 2013.

[2] T.S. Rappaport, Y. Xing, G.R. MacCartney, A.F. Molisch, E. Mellios, J. Zhang, "Overview of Millimeter Wave Communications for Fifth-Generation (5G) Wireless Networks with a Focus on Propagation Models", IEEE Transactions on Antennas and Propagation, vol. 65, no. 12, pp. 62136230, 2017.

[3] M. Jacob, S. Priebe, R. Dickhoff, T. Kleine-Ostmann, T. Schrader, T. Kurner, "Diffraction in $\mathrm{mm}$ and sub-mm Wave Indoor Propagation Channels", IEEE Transactions on Microwave Theory and Techniques, vol. 60, no. 3, pp. 833-844, 2012.

[4] M. Ghaddar, L. Talbi, T.A. Denidni, A. Sebak, "A Conducting Cylinder for Modeling Human Body Presence in Indoor Propagation Channel”, IEEE Transactions on Antennas Propagation, vol. 55, no. 11, pp. 3099-3103, 2007.

[5] C. Gustafson, F. Tufvesson, "Characterization of $60 \mathrm{GHz}$ Shadowing by Human Bodies and Simple Phantoms”, Radioengineering, vol. 21, no. 4, pp. 979-984, 2012.

[6] G.R. MacCartney, S. Deng, S. Sun, T.S. Rappaport, "Millimeter-wave human blockage at 73 ghz with a simple double knife-edge diffraction model and extension for directional antennas", IEEE 84th Vehicular Technology Conference (VTC-Fall), Montreal-Canada, 2016, pp. 1-6.

[7] X. Zhao, Q. Wang, S. Li, S. Geng, M. Wang, S. Sun, Z. Wen, "Attenuation by Human Bodies at 26- and 39.5-GHz Millimeter Wavebands", IEEE Antennas Wireless Propagation Letters, vol. 16, pp. 1229-1232, 2016.

[8] X. Chen, L. Tian, P. Tang, J. Zhang, "Modelling of human body shadowing based on $28 \mathrm{ghz}$ indoor measurement results", IEEE 84th Vehicular Technology Conference (VTC-Fall), MontrealCanada, 2016, pp. 1-5.

[9] W. Qi, J. Huang, J. Sun, Y. Tan, C. Wang, X. Ge, "Measurements and modeling of human blockage effects for multiple millimeter wave bands", 13th International Wireless Communications and Mobile Computing Conference (IWCMC), Valencia, Spain, 2017, pp. 1604-1609.

[10] Y. Dalveren, A.H. Alabish, A. Kara, "A Simplified Model for Characterizing the Effects of Scattering Objects and Human Body Blocking Indoor Links at 28 Ghz", IEEE Access, vol. 7, pp. 69687-69691, 2019.

[11] A. Kara, H.L. Bertoni, "Effect of People Moving Near Short-Range Indoor Propagation Links at 2.45 GHz", Journal of Communications and Networks, vol. 8, no. 3, pp. 286-289, 2006. 
[12] A. Kara, "Human Body Shadowing Variability in Short-Range indoor Radio Links at 3-11 GHz band”, International Journal of Electronics, vol. 96, no. 2, pp. 205-211, 2009.

[13] J.S. Romero-Peña, N. Cardona, "Applicability limits of simplified human blockage models at 5G mm-wave frequencies", 13th European Conference on Antennas and Propagation (EuCAP), Krakow-Poland, 2019, pp. 1-5.

[14] G.L. James, Geometrical Theory of Diffraction for Electromagnetic Diffraction, 3rd ed., London, United Kingdom, The Institution of Engineering and Technology (IET), 2007.

[15] P. Karadimas, B. Allen, P. Smith, "Human Body Shadowing Characterization for $60-\mathrm{GHz}$ Indoor Short-Range Wireless Links", IEEE Antennas Wireless Propagation Letters, vol. 12, pp. 16501653, 2013.

[16] H.L. Bertoni, Radio Propagation for Modern Wireless Systems, 1st ed., London, United Kingdom, Prentice Hall, 2000. Böl. 6, pp. 143-144. 